\title{
Jamaican Leaders
}




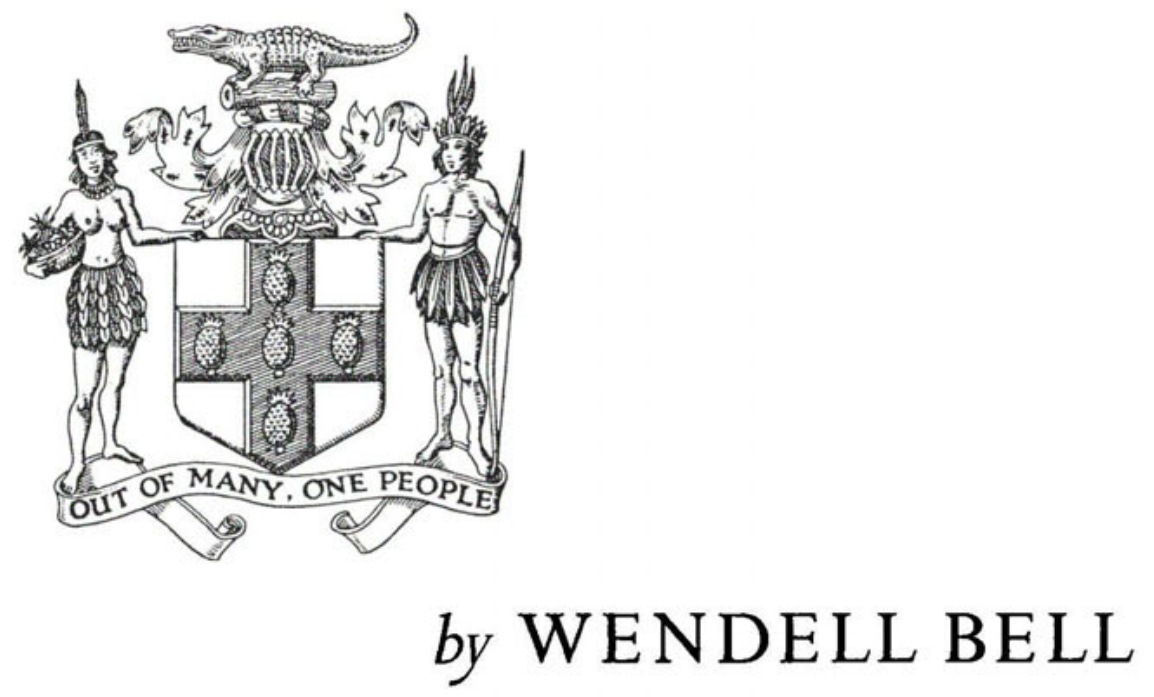




\section{Jamaican}

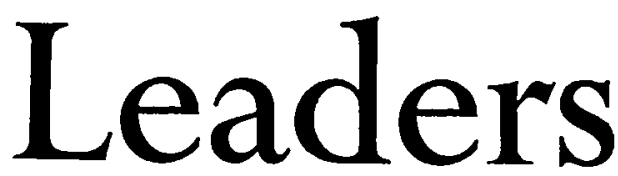

\section{POLITICAL ATTITUDES IN A NEW NATION}

UNIVERSITY OF CALIFORNIA PRESS

Berkeley and Los Angeles, 1964 
UNIVERSITY OF CALIFORNIA PRESS

BERKELEY AND LOS ANGELES, CALIFORNIA

CAMBRIDGe UNIVERSITY PRESS, LONDON, ENGLAND

(C) 1964 BY THE REGENTS OF THE UNIVERSITY OF CALIFORNIA

LIBRARY OF CONGRESS CATALOG CARD NUMBER: 64-19447

PRINTED IN THE UNITED STATES OF AMERICA 
To LORA-LEE, SHARON, and DAVID 
